\title{
Comparing and Scoring Selected Four Train Ticketing Mobile Phone Applications
}

\author{
Vaishnavi Venugopalan, Chaitanya Vyas* \\ School of Liberal Studies, Pandit Deendayal Petroleum University, Gujarat, India \\ vaishnavi.vsls13@sls.pdpu.ac.in, chaitanya.vyas@sls.pdpu.ac.in
}

\begin{abstract}
To find the best train ticket booking mobile application on the bases of application features. Four widely used mobile phone applications (Ixigo, MakeMyTrip, ClearTrip, and IRCTC) for railway ticket booking are selected and application features related to ease of download and use, rating, number of installs, etc. are compared. A practical attempt is made to book a train ticket using all these applications one by one and comparing features such as coach locator, platform locator, route map, fare break-up, showing seat availability, save and pre-fill passenger details, sort search list by train name/number, sort search list by journey duration, sort search list by class, train running status, etc. 1 point is allotted to the applications if a particular feature is available in the applications and 0 is allotted if the feature is not available. Sum of all the points is calculated separately for each application and then ranks are given from 1 to 4 considering the final score. Ixigo mobile application scores the highest among other three train ticketing mobile applications MakeMyTrip, ClearTrip, and IRCTC. Features such as downloading applications via a miss call or SMS; downloading application from websites of Ixigo, MakeMyTrip, ClearTrip, and IRCTC; and sorting train search list by class on applications are not found in any of these four applications. Furthermore, features are grouped into groups such as - the features only available in top ranking Ixigo and the features not available in top ranking Ixigo but available in any or all other three applications. This research will be of a good value for mobile railway ticket booking application providers as competition is becoming acute and the booking pattern is shifting from using desktop or laptop to mobile phones and tablets.
\end{abstract}

Keywords: Train ticketing, applications, Ixigo, MakeMyTrip, ClearTrip, IRCTC

\section{Introduction}

In the concluding chapter of the book titled Mobile Design and Development: Practical concepts and techniques for creating mobile sites and web apps, author Brian Fling writes "I like to think about what's next and what tomorrow's innovations will be. A question I get asked a lot is 'What will the future of mobile be?' The best answer I can think of that comes close to capturing the potential those mobile offers is simply 'Everything'." This note from the book on mobile sites and applications tells much about how cell phone applications are changing customers' experiences and expectations of satisfying their needs of buying range of goods and services, from groceries, healthcare products, electronic goods, clothes to travelling. Not only travel or leisure related but mobile applications related to emergency and health services are also becoming popular and a matter of everyday use. There are more than 40,000 mobile applications related to health and roughly 247 million users downloaded one or the other application (West, 2012). Not only to the patients or health cautious users, these applications also increase efficiency of medical practitioners too. Some systems in the field of cardiology have significant research and apps are available (Martínez-Pérez et al., 2014). There were 710 apps related to cardiology and heart disease available by May 2013. The potential worth of the mobile application industry was once estimated to reach as $\$ 100$ billion by the year 2015 (Rakestraw et al., 2013). Witnessing extraordinary growth and proliferation of smart phones, mobile application business is growing leaps and bounds. Ease of downloading applications, storage power of cell phones, data transfer speed, connectivity and other favorable factors motivate users to download, use, and spread a word about usefulness of mobile applications. Shekhar (2014) referring to mobile industry forecast, notes that application download was projected to grow at a rate of $92 \%$ per annum i.e. from 7 billion downloads in 2009 to nearly 50 billion downloads in 2012. A research company named ABI Research forecast that revenue generated from mobile applications will reach to $\$ 46$ billion in the year 2016. India is not an exception in the acceptance of mobile applications. Train ticket booking in India has witnessed a sea change in last one decade. Though India saw this transformation not so early unlike other countries, passengers have always been remained in the focus while developing infrastructure or customer convenience. Indian Railways, which is a 
public sector enterprise managed by Ministry of Railways, Government of India, was running 11,824 trains in 2010-11 and today runs 19,000 trains (www.indianrailways.gov.in).

Indian Railways ranks fourth when length of railways measured in kilometers; being the United States, China, and Russia first, second, and third respectively. The transformation has been passed through vending railway tickets at railway station windows manually to making reservation computerized, online booking through www.irctc.co.in, and now via IRCTC (Indian Railway Catering and Tourism Corporation) mobile application. From personally visiting railway stations to buy tickets, passengers' preference is shifting to use train ticketing websites or mobile applications on their cell phones or tablets. IRCTC carried 7,651 passengers in the year 2010-11 and today 23 million passengers buy railway ticket daily (www.indianrailways.gov.in). This figure was 1,284 passengers in 1950-51. It made 294 computerized reservation offices functional during 2010-11. In 2013-14 it had seat/berth capacity of 5,171,547. Year 2015 Whitepaper of Indian Railways noted "...ease of booking tickets are issues that need urgent attention." There are many train ticket booking applications available on application platform such as Android, iOS, and Windows. Among many, popular ticketing applications are Ixigo, MakeMyTrip, ClearTrip, and IRCTC (Choudhary \& Sachan, 2013). Though Ixigo redirects to IRCTC for making payment and booking tickets, feature-wise it is the best application. It searches and compares the most useful information required for train ticketing. Mr. Aloke Bajpai and Mr. Rajnish Kumar launched Ixigo in 2007. NASSCOM enlisted Ixigo in the Top 10 Emerging Company in India in 2010 and in 2012, it featured in BBC World's Fast Track list of globally most innovative products. Ixigo goes beyond just ticket booking by providing trip related information like accommodation, food, sight-seeing, travel tips to help users plan and enhance their travel experience. Companies such as SAIF Partners, MakeMyTrip Ltd., and Micromax Informatics Ltd. have invested in Ixigo. Founded in the year 2000 by Deep Kalra, MakeMyTrip Limited provides access to airlines operating in India, airlines connected to India, more than 83,000 hotels in and outside India, Indian Railways, and to bus operators in India. After in U.S., MakeMyTrip began operations in India in the year 2005. Besides through its website and application, MakeMyTrip operates also through retail franchise and affiliates. It has offices in 20 Indian cities. Founded by its CEO Stuart Crighton, ClearTrip has developed award winning applications and website. Its products include flights, hotels, and train booking. ClearTrip has three offices in India.

\section{Literature Review}

Nysveen, Pedersen, \& Skard (2015) reviewed research conducted on mobile services. Finding research gaps, authors suggested future research on mobile applications. In their research work, authors found that studies on mobile services were largely described in a generic way about m-commerce, mobile marketing, data services etc. Literature, largely quantitative studies, focused mainly on definitions, opportunities, and challenges of mobile services, success criteria, implications, system design, and on modeling processes. The research gaps identified was that there were fewer studies on mobile application-based services, on effects of mobile service usage, and on services in context. Authors anticipated increase in number of mobile services in future and observed lack of research with experimental design used. The study quantitatively and qualitatively examined the rise of mobile phones and mobile internet services (mobile commerce and mobile marketing) globally. Based on a conceptual review of 212 articles, the study outlined factors critical to the success of mobile marketing services, in terms of adoption of these services by the market. The factors were related to resolutions of challenges such as personalization, multiple devices, security, message, and sound. The study found influences of subjective norms, perceived usefulness, ease of use, and enjoyment on attitude to use while behavioral control and usefulness were significant antecedents of intention to use mobile apps. Usefulness, gender, income, and intention to use were revealed as antecedents of actual usage of mobile apps. The study noted a work on direct or indirect influences of monetary value, network factors, interface convenience, context controllability, usefulness, ease of use, continued intention to use, influences of enjoyment, network externalities, usefulness, communication effectiveness, and service costs. Mobile phone applications have become a selling point for devices. Rakestraw et al. (2013) developed a case study on mobile application industry, which was predicted to be $\$ 100$ billion worth and still growing. The study elaborated on boost given to mobile applications by smart phones; the changed way of accessing internet, games, and social networking, and on how Android and iOS have created differentiation through application development, availability of distinctive applications, and through selling platforms. Amidst the presence of niche players and predicted positive future, there are obstacles present such as privacy and security issues 
among other issues. Apart from entertainment purposes, applications are also playing life saving role. Martínez-Pérez et al. (2014) compared research magnitude in various geographic areas according to income and mobile applications developed for fatal health conditions.

Banerjee \& Lennon (2012) studied M-commerce evolution in India. The authors examined CLIP (Communication, Location, Information, and Payment) framework and found that integral aspect was present of communication with ABN AMRO India's and Aviva's customer management, of location with order fulfillment of HP, of information with ICI Paint's sales reporting, and of payment with gaming and music services. There has been a phenomenon growth observed among number of internet users and mobile phone users, and online buyers in India. Ghosh (2014) analyzed the reasons for e-commerce in India being not able to achieve targeted level. The study also included trend of consumers' online buying behavior in India. Positively and negatively influencing variables with reference to socio-cultural in India, encouraging or discouraging buyers, are identified. Variety of factors affecting online buying behavior are researched, age being one of them. A study noted that use of smart phones, related with use of mobile applications in India, has been extensive among Gen Y users (Bhave, Jain \& Roy, 2013). Applying Focus Group Discussion and indepth interview methods, these authors attempted to understand Gen Y users' attitude towards applications and advertisement. Determinants behind forming the attitude were identified. Widely accepted by young customers, increase in sales of smart phones is discouraging sales of some products while encouraging sales of other products. Natarajan and Kumar (2013) observed significant growth of mobile payment and mobile banking and linked it with penetration of smart phones in India. Authors observed that $\mathrm{m}$-commerce in India included travel and ticketing, utility bill payments, merchant and retail transactions, and money transfers. Evolution of M-commerce in India is due to assembling of MSP (Mobile Service Providers), banks, and of payment service providers. Web traffic coming up from mobile phones was predicted to be $50 \%$ by the year 2013. Penetration of cell phones in India was estimated to be $60 \%$ and was expected to touch $90 \%$ by the year 2015. Approximately $80 \%$ of size and growth of e-commerce in India, calculated as 500 billion INR in 2011, was related to air ticketing, rail ticketing, hotel bookings, recharge, etc. Internet and reference group as sources of information are vital for travelers.

Verma, Stock, \& McCarthy (2012) observed preference of search on internet and devices used by travelers. This research with a sample of 2,830 respondents revealed that business travelers relied on their employer's recommendations about hotel stays besides their collection of information about hotels and online travel agents via internet search engines. On the other hand, leisure travelers gave importance to the advices by their colleagues and friends. Travel websites, search engines, and online travel agents were next important sources. Company websites, online travel agents, and websites such as TripAdvisor are preferred in post information collection stage. Originally a calling and texting device, mobile phones are now handy platform for making payments for different services availed. Balaji \& Babu (2013) explored the concept of m-wallet as a mobile phone based e-ticketing. The paper focused on the creation of a mobile wallet ( $\mathrm{m}$-wallet) for mobile transactions, and saw it as a necessity in an era of $3 \mathrm{G}$ and wireless internet services. Moreover, e-ticketing showed a broad and promising future, as it offers a safer, convenient, and low-cost alternative to the conventional form of ticketing. The authors aimed to provide an integrated platform for both ticketreservations and non ticket-reservations, using an MWALLET. mWallet would be a universal mobile ticketing platform, supported by external environments. mWallet aims to overcome the weaknesses of existing ticketing systems, and e-ticketing systems including the greater, pressing problems of convenience of security. The world today is becoming increasingly app-savvy. The research paper by Inukollu at el. (2014) recognized the role of good mobile applications in consumers' daily life, and analyzed the mobile application business from the point of view of the end-user as well as from the developers'. Through surveys and observations, the authors identified the causes for an app being called "bad/low quality", and how best to avoid this tag. The authors also acknowledged that with the presence of thousands of mobile applications today, app developers must keep an open mind and embrace continual innovations in the life-cycle of the app. This is the only way to stay abreast of the app-game and compete with the numerous apps entering the market every day. Enhancing consumer satisfaction has to be kept at the crux of it. Moreover, continual innovation, and new entrants promise a dynamic, eventful and interesting future for mobile applications. With increasing tourism around the globe, increasing use of mobile applications, mobile services in day-today activities, all activities and events becoming exceedingly experiential; a paper by Lim (2012) provided an exceedingly contextual view of mobile tourism activities. The paper proposed a theoretical approach for 
designing mobile tourism applications using situation awareness i.e. it tried to develop contextual awareness of mobile applications that will improve a traveler's situation awareness before, during, and post-travel. Three hypothetical scenarios were presented, discussed, and measured to create situational awareness.

\section{Methodology}

Descriptive research design is used in this research. Data on features of the mobile applications are collected by actually downloading and using these applications on phones. Scoring pattern follows allotting 0 or 1 to the mobile application according to availability of the features. The features are related to downloading and using the applications (Table 1) and facilities provided by the applications (Table 2). For each available feature the application is given point 1 , and 0 is given for each missing feature. Column-wise sum of score is taken for the application and the same is repeated for all the mobile application. The application with the highest score is ranked 1 , followed by ranks 2 , and 3 . Application with lowest score is ranked $4^{\text {th }}$. The features listed in Table 1 are explained below:

- Download app via miss-call or text message: Receiving a link for downloading application via text/SMS or via giving a missed call to a given number.

- Download app from website: Downloading application from download link given on company's website.

- App Ratings: Ratings given to mobile applications by their users, as seen on Google Play store.

- No. of installs: Number of application installs, as seen on Google Play store.

- Size of App: The size the application occupies in phone memory. The smaller the application size, higher the rank allotted.

- OS Compatibility: Cross-platform compatibility of mobile applications on phones based on Android, iOS or Windows operating systems.

- Send feedback: Provision in applications for users to be able to provide feedback to developers and organization.

The features listed in Table 2 are explained below:

- Coach locator: Virtual map of where the coach will be located on platform when the train arrives.

- Platform locator: Predicts which platform the selected train will arrive on.

- Route Map: Shows a map of the route the train will take during its journey.

- Fare Break-up: Shows what portion of the fare the passenger pays is charged for. For example, base fare, tax, services charges etc.

- Showing seat availability: Shows number of seats available on a certain train.

- Save and pre-fill passenger details: This provides the provision of saving passenger details such as name, age, contact number etc. and fills these details automatically at every new ticket booking is made by a regular user.

- Search by train name/number: Look for trains by providing input of train name or number, rather than searching for all trains between the desired stations.

- Sort search list by train name/number: Sorts the list of trains in ascending or descending order according to the train names and according to train numbers.

- Sort search list by journey duration: Sorts the search list in ascending or descending order, by the time taken in the journey.

- Sort search list by class: Orders search list according to the class of tickets available.

- Train running status: Shows the real time information about status of trains.

- Train reviews: Shows passenger reviews about trains by different parameters.

- Train ratings: Shows star ratings of trains, given by passengers.

- Sort search list by arrival/departure time: Order search list by time of arrival of train, or time of departure.

- Sort search list by number of stops: Order search list by the number of stops each train makes between the origin and destination stations.

- Show days of train running without selecting journey date: Shows train weekly schedule without required to enter travel dates. 
- Search trains by station: Provides a list of all trains arriving at a particular station even within selecting a time.

- Station alarm: Alerts certain distance before reaching specified station.

- Seat map: Shows a virtual map of the train and helps locate the seat.

- Local and metro train searcher: Provides search facilities for local trains and metros as well.

- Save favorite trains: Allows users to save certain trains as favorite and minimizes time and efforts to search for the train at the time of subsequent trips.

- Find hotels around stations: Allows users to locate hotels close to railway stations.

- Shows rescheduled/cancelled trains: Shows all trains that have been rescheduled or cancelled within a certain time frame.

- Train tips: Provides tips for rail travel.

- Current availability: Shows whether number of trains running currently from a certain station have available seats.

- Booking via app: Offers not only train or availability searching on application but also booking and payment facility on application.

- Book ticket for round trip: Tickets can be booked for the return trip as well.

- Berth preference: Asks for berth preference such as lower, middle, upper, side lower, side upper berth etc.

- Shows number of trains: Shows total number of trains running between selected stations.

- Payment modes: Shows available options of payment while booking.

- Details of bank transaction charges: Shows the details of how much banks charge for the transactions.

- Reservation preferences: Provides the option of booking tickets only if a particular berth preference is available.

\section{Results and Discussion}

As shown in Table 1, MakeMyTrip mobile application scores the highest ( 9 points) in terms of ease of downloading and using this application. Though MakeMyTrip application has certain missing features, as shown in Table 2. It does not scores high for application rating received on Google Play Store and scores the least for occupying small size on users' phones or tablets. Remaining applications Ixigo, ClearTrip, and IRCTC score 8,6 , and 7 points respectively.

Table 1: Downloading and using applications

\begin{tabular}{llllll}
\hline S/N & Application Features & \multicolumn{2}{l}{ Mobile Applications } & & \\
& & Ixigo & MakeMyTrip & ClearTrip & IRCTC \\
\hline 1 & Download app via miss-call or SMS & 0 & 0 & 0 & 0 \\
2 & Download app from website & 0 & 0 & 0 & 0 \\
3 & App Ratings (Play Store Data) & 1 & 3 & 2 & 4 \\
4 & No. of installs & 2 & 1 & 1 & 1 \\
5 & Size of App & 3 & 4 & 2 & 1 \\
6 & OS Compatibility & 1 & 0 & 0 & 0 \\
7 & Send feedback & 1 & 1 & 1 & 1 \\
A & Score & 8 & 9 & 6 & 7 \\
\hline
\end{tabular}

Table 2 shows comparison and allotment of points to four mobile applications on the bases of features provided by respective applications once the applications are downloaded on to mobile phones or tablets. Ixigo scores highest ( 25 points), followed by MakeMyTrip scoring second with 11 points. ClearTrip and IRCTC mobile applications stand with equal 11 points. 
Table 2: Application features

\begin{tabular}{|c|c|c|c|c|c|}
\hline \multirow[t]{2}{*}{$\mathbf{S} / \mathbf{N}$} & \multirow[t]{2}{*}{ Application Features } & \multicolumn{4}{|c|}{ Mobile Applications } \\
\hline & & Ixigo & MakeMyTrip & ClearTrip & IRCTC \\
\hline 1 & Coach locator & 1 & 0 & 0 & 0 \\
\hline 2 & Platform locator & 1 & 0 & 0 & 0 \\
\hline 3 & Route Map & 1 & 0 & 0 & 0 \\
\hline 4 & Fare Break-up & 1 & 1 & 1 & 1 \\
\hline 5 & Showing seat availability & 1 & 1 & 1 & 1 \\
\hline 6 & Save and pre-fill passenger details & 1 & 0 & 0 & 1 \\
\hline 7 & Search by train name/no. & 1 & 1 & 0 & 0 \\
\hline 8 & Sort search list by train name/no. & 1 & 0 & 0 & 1 \\
\hline 9 & Sort search list by journey duration & 1 & 1 & 1 & 0 \\
\hline 10 & Sort search list by class & 0 & 0 & 0 & 0 \\
\hline 11 & Train running status & 1 & 0 & 1 & 0 \\
\hline 12 & Train reviews & 1 & 0 & 0 & 0 \\
\hline 13 & Train ratings & 1 & 0 & 0 & 0 \\
\hline 14 & Sort search list by arrival/departure time & 1 & 1 & 1 & 1 \\
\hline 15 & Sort search list by no. of stops & 1 & 0 & 0 & 0 \\
\hline 16 & $\begin{array}{l}\text { Show days of train running without selecting } \\
\text { journey date }\end{array}$ & 1 & 0 & 0 & 0 \\
\hline 17 & Search trains by station & 1 & 0 & 0 & 0 \\
\hline 18 & Station Alarm & 1 & 0 & 0 & 0 \\
\hline 19 & Seat map & 1 & 0 & 0 & 0 \\
\hline 20 & Local and metro train searcher & 1 & 0 & 0 & 0 \\
\hline 21 & Save favorite trains & 1 & 0 & 0 & 0 \\
\hline 22 & Find hotels around stations & 1 & 0 & 0 & 0 \\
\hline 23 & Shows rescheduled/cancelled trains & 1 & 0 & 0 & 0 \\
\hline 24 & Train tips & 1 & 0 & 0 & 0 \\
\hline 25 & Current availability & 1 & 0 & 0 & 0 \\
\hline 26 & Booking via app & 0 & 1 & 1 & 1 \\
\hline 27 & Book ticket for round trip & 0 & 1 & 0 & 0 \\
\hline 28 & Berth preference & 0 & 1 & 1 & 1 \\
\hline 29 & Shows number of trains & 0 & 1 & 0 & 0 \\
\hline 30 & Payment modes & 1 & 2 & 3 & 1 \\
\hline 31 & Details of bank transaction charges & 0 & 0 & 0 & 1 \\
\hline 32 & Reservation preferences & 0 & 0 & 0 & 1 \\
\hline B & Score & 25 & 11 & 10 & 10 \\
\hline
\end{tabular}

Adding scores of Table 1 and Table 2, the final ranking to mobile applications are given, as shown in Table 3. Ixigo ranks number 1 , followed by MakeMyTrip ranking $2^{\text {nd }}$, and IRCTC and ClearTrip ranking $3^{\text {rd }}$ and $4^{\text {th }}$ respectively.

Table 3: Total score

\begin{tabular}{|c|c|c|c|c|}
\hline Ranking & Ixigo & MakeMyTrip & ClearTrip & IRCTC \\
\hline $\begin{array}{l}\text { Score on downloading and using applications (Table } \\
\text { 1) }\end{array}$ & 8 & 9 & 6 & 7 \\
\hline Score on application features (Table 2) & 25 & 11 & 10 & 10 \\
\hline Total Features Score & 33 & 20 & 16 & 17 \\
\hline App ranks according to score & 1 & 2 & 4 & 3 \\
\hline
\end{tabular}

Ixigo offers highest number of the features and IRCTC offers the least. Further, two examinations are made such as list of features not present in any of the four mobile applications compared here, and the features absent in top ranked application Ixigo. The following three features are not available with any of the four mobile applications: 
- Download app via miss-call or SMS

- Download app from website

- $\quad$ Sort search list by class

Table 4 enlists the features missing in the top ranked mobile application here i.e. Ixigo while Table 5 shows the list of features provided by Ixigo application only among four applications.

\section{Table 4: Features not present in top ranked app Ixigo}

\begin{tabular}{ll}
\hline S/N & Features \\
\hline 1 & Download app via miss-call or SMS \\
2 & Download app from website \\
3 & Sort search list by class \\
4 & Booking via app \\
5 & Book ticket for round trip \\
6 & Berth Preference \\
7 & Shows number of trains \\
8 & Details of Bank Transaction Charges \\
9 & Reservation Preferences \\
\hline
\end{tabular}

Table 5: Features available only in Ixigo application

\begin{tabular}{ll}
\hline S/N & Features \\
\hline 1 & Coach locator \\
2 & Platform locator \\
3 & Route Map \\
4 & Train reviews \\
5 & Train ratings \\
6 & Sort search list by no. of Stops \\
7 & Show days of train running without selecting journey date \\
8 & Search Trains by station \\
9 & Station Alarm \\
10 & Seat Map \\
11 & Local and Metro Train Searcher \\
12 & Save Favorite Trains \\
13 & Find hotels around station \\
14 & Shows rescheduled/cancelled trains \\
15 & Train Tips \\
16 & Current Availability \\
\hline
\end{tabular}

\section{Conclusion}

Using mobile phone applications for train ticket booking is not totally a new phenomenon in India. Train ticket booking experience in India has traverses from personally buying tickets by visiting railway station to booking using World Wide Web and now to using ubiquitous cell phones and tablets. Passengers expect mobile ticket booking platforms with as many features as can provide effortless and quick ticket booking. Mobile ticket booking applications such as Ixigo, MakeMyTrip, ClearTrip, and IRCTC are popular applications among all. Features such as users' convenience to download application via sending a text (SMS) or giving a miscall to a phone number, downloading from websites, size of application, and compatibility with users' cell phone operating systems play important role in addition to the rating received by applications on App Store, Play Store, or Windows Store; or number of installs or number of stars received by the applications. Number of features offered by one application gives competitiveness over others. It was found that Ixigo scores highest among remaining three train ticketing mobile applications namely MakeMyTrip, ClearTrip, and IRCTC in terms of number of features offered. While there are nine features which are not present even in top ranked Ixigo, there are sixteen features which are present only in Ixigo, which makes it top ranked application. Ixigo does not provide selecting berth preference which is present in remaining three competing 
applications, besides its limitation to not booking the tickets directly but redirecting to IRCTC. The best train ticketing mobile application can be the one which has all the features that Ixigo application has plus three features such as downloading application via a miss-call or sending text/SMS, downloading application from booking website, and a feature of sorting train search list by train classes.

\section{References}

Balaji, T. K. \& Babu, J. V. (2013). MWALLET: A Mobile based E-Ticketing System with Push Technology. International Journal of Conceptions on Electrical and Electronics Engineering, 1(1), 74-79.

Banerjee, S. \& Lennon, M. (2012). India: The Awakening of M-Commerce. M-commerce: Global Experiences and Perspectives. Hershey PA: Idea Group, Chapter VIII, 134-157.

Bhave, K., Jain, V. \& Roy, S. (2013). Understanding the orientation of Gen Y toward mobile applications and inapp advertising in India. International Journal of Mobile Marketing, 8(1), 62-74.

Choudhary, S. \& Sachan, A. (2013). A Review on Online Travel and Tourism Industry in Indian Context. Productivity, 53(4), 303-310

Fling, B. (2009). Mobile Design and Development: Practical concepts and techniques for creating mobile sites and web apps. O'Reilly Media, Inc.

Ghosh, D. (2014). Why Indian e-retailing market is still a partly success and a partly failure story? Journal of Account Mark, 3(113), 2. http://dx.doi.or/10.4172/2168-9601.1000113

http://indianrailways.gov.in/railwayboard/uploads/directorate/stat_econ/yearbook1011/Passenger_business.pdf [accessed on Feb 10, 2016]

http://www.cleartrip.com/about/ [accessed on Feb 7, 2016]

http://www.indianrailways.gov.in/railwayboard/uploads/directorate/finance_budget/Budget_201516/White_Paper-_English.pdf [accessed on Feb 12, 2016]

http://www.irctc.com/aboutUs_En.jsp [accessed on Feb 9, 2016]

https://www.ixigo.com/html/info/about.ixi [accessed on Feb 9, 2016]

https://www.makemytrip.com/about-us/company_profile.php [accessed on Feb 8, 2016]

Inukollu, V., Keshamoni, D., Kang, T. \& Inukollu, M. (2014). Factors influencing quality of mobile apps: Role of mobile app development life cycle, 5(5), 15-34.

Lim, T. (2012). Designing the next generation of mobile tourism application based on situation awareness. Network of Ergonomics Societies Conference (SEANES), Southeast Asian, 1-7.

Martínez-Pérez, B., de la Torre-Díez, I., López-Coronado, M. \& Sainz-De-Abajo, B. (2014). Comparison of mobile apps for the leading causes of death among different income zones: a review of the literature and app stores. JMIR mHealth and uHealth, 2(1).

Natarajan, M. \& Kumar, S. (2013). Mobile Market Dynamics in India: A New Marketing Paradigm. International Journal of Applied Services Marketing Perspectives, 2(2).

Nysveen, H., Pedersen, P. \& Skard, S. (2015). A review of mobile services research: Research gaps and suggestions for future research on mobile apps.

Rakestraw, T., Eunni, R. \& Kasuganti, R. (2013). The mobile apps industry: A case study, R. Journal of Business Cases and Applications, 9, 1-26.

Shekhar, S. (2014). A Study of Mobile Apps Industry. IRJA-Indian Research Journal, 1(6),

Verma, R., Stock, D. \& McCarthy, L. (2012). Customer preferences for online, social media, and mobile innovations in the hospitality industry. Cornell Hospitality Quarterly, 53(3), 183-186.

West, D. (2012). How mobile devices are transforming healthcare. Issues in technology innovation, 18(1), 1-11. 